\title{
Preparation and Properties of a Novel Type of Tannin-based Wood
}

\section{Adhesive}

Xinyi Chen ${ }^{1,2}$, Antonio Pizzi ${ }^{2}$, Emmanuel Fredon ${ }^{2}$, Christine Gerardin ${ }^{3}$, Jinxing Li $^{1}$, Xiaojian $\mathrm{Zhou}^{1}$, Guanben $\mathrm{Du}^{1}$

1 Key Laboratory for Forest Resources Conservation and Utilisation in the Southwest Mountains of China (Southwest Forestry University), Ministry of Education, Kunming 650224, PR China

2 LERMAB, University of Lorraine, 27 rue Philippe Seguin, BP 1041, 88051 Epinal, France

3 LERMAB, University of Lorraine, Boulevard does Aiguillettes, 54000 Nancy, France

* Corresponding Author: A.Pizzi. Tel.: +33-623126940. E-mail address: antonio.pizzi@univ-lorraine.fr 


\begin{abstract}
:
A novel biomass-based wood adhesive was prepared with commercial Mimosa tannin extract and glycerol diglycidyl ether (GDE) by convenient mechanical mixing. GDE served as the crosslinker of the tannin without any aldehyde addition yielding hardened three-dimensional networks. Different weight ratios of tannin/GDE were investigated by a number of techniques to determine their influence on final properties. The results showed that a non-hydrolysable ester bonds can be formed between the epoxy groups of GDE and hydroxyl groups of tannin, this being the critical factor for the good water resistance obtained by the wood adhesives prepared. Moreover, the dry and wet shear strength exhibit positive correlation with the proportion of GDE added. Even at a relatively small proportion of GDE (33\% of the weight of dry tannin), the dry and $24 \mathrm{~h}$ cold water shear strengths of the bonded plywood satisfied the requirements of relevant standard (GB/T 9846-2015, $\geqslant 0.7 \mathrm{MPa})$. The thermal stability of the tannin-based wood adhesive so prepared progressively improved with the increasing proportion of GDE.
\end{abstract}

Key words: Mimosa tannin, Glycerol diglycidyl ether (GDE), Biomass wood adhesive, Water resistance 


\section{$1 \quad 1$ Introduction}

2 The topic of environmental and eco-friendly wood adhesive is now one of the hottest

3 subject and an unavoidable one in the wood industry ${ }^{[1]}$. Nowadays,

4 formaldehyde-based wood adhesives are so widely applied derive from their low cost,

5 short curing time and strong adhesion ${ }^{[2,3]}$. And the formaldehyde-based adhesives are

6 account for almost $90 \%$ of totally wood adhesives industry ${ }^{[3]}$. Nevertheless, traditional

7 synthetic wood adhesives present two main drawbacks, these being their toxic starting

8 materials (i.e. formaldehyde and phenol) and formaldehyde-emission during their use

9 and for long time afterward. Therefore, these drawbacks have created a demand for

10 adhesives prepared from non-toxic and inexpensive materials to replace them.

11 Now, for a number of years, some biomass resources, including lignin ${ }^{[4-7]}, \operatorname{tannin}^{[8-10]}$,

$12 \operatorname{protein}^{[11-13]}$, non-food $\operatorname{starch}^{[14,15]}$ and agricultural or forest residues ${ }^{[16-18]}$, have

13 attracted the attention of researchers to prepare some high-performance wood

14 adhesives. Among these, condensed tannins have been considered to have some

15 interesting features to prepare wood adhesive ${ }^{[19]}$. Initially, condensed tannins phenolic

16 nature led to their use to prepare adhesives similar to phenol-formaldehyde (PF) wood

17 adhesive $\mathrm{e}^{[8-10,19,20]}$. It is encouraging that tannin-formaldehyde wood adhesives have

18 been successful commercially for many years ${ }^{[19]}$. However, formaldehyde, was still an

19 essential component, even though formaldehyde-emission has been improved by

20 some extent ${ }^{[21]}$. Therefore, low or no aldehyde tannin adhesives have been developed

21 by a number of approaches. Hexamethylenetetramine (hexamine) ${ }^{[22,23]}$, glyoxal ${ }^{[24]}$, 
22 furfuryl alcohol ${ }^{[25]}$, polymeric diphenylmethane diisocyanate (p-MDI) ${ }^{[23,26]}$,

23 poly-ethylenimine $(\mathrm{PEI})^{[27]}$, as well as carbohydrates-generated non-toxic and

24 non-volatile aldehydes by specific oxidation ${ }^{[28]}$, were used to react with different

25 condensed tannins to produce tannin-based wood adhesive without any kinds of

26 volatile and toxic aldehydes. Certainly, some tannin wood adhesives were obtained

27 though biomass resources (starch) mixing with condensed tannin, and alternative

28 aldehydes acting as cross-linkers, leading to low formaldehyde emission ${ }^{[13,29-31]}$.

29 Apparently, these improved adhesive formulations reduced effectively the toxic

30 raw-materials consumption and formaldehyde-emission, as well as increasing biomass

31 content.

32 Herein, a novel, high-bonding performance tannin-based wood adhesive has been

33 synthesized by manual or mechanical mixing without any pre-treatments. The

34 cross-linker used is a commercial product, namely glycerol diglycidyl ether (GDE).

35 Three tannin-based adhesives with different weight ratios of tannin/GDE were studied,

36 from a high 1/1 tannin/GDE ratio to lower GDE proportions. Their properties were

37 studied, including shear strength, hydrolysis residual rate, physico-chemical features

38 and thermal stability. Furthermore, the reaction mechanism of tannin and GDE was

39 confirmed by FT-IR, MALDI-TOF and solid status ${ }^{13} \mathrm{C}$ NMR.

\section{2. Materials and methods}

\subsection{Preparation of tannin-based wood adhesives}

42 The series Mimosa tannin-based wood adhesives were obtained by mixing tannin and 
43 GDE directly at room temperature without any pre-synthesis. Briefly, taking a certain

44 amount of Mimosa tannin (Acacia mearnsii de Wildt) extract, supplied by Silva

45 Chimica, St. Michele Mondovi, Italy) and then put them into a $100 \mathrm{~mL}$ plastic bottle.

46 Thereafter, some amount of distilled water (Laboratory homemade) was added,

47 stirring sufficiently by hand till a homogeneous tannin/water mixture was obtained.

48 After that, setting a weight of glycerol diglycidyl ether (GDE, technical grade,

49 obtained from Sigma-Aldrich) was added to the tannin/water mixture up to when a

50 homogeneous tannin/GDE/water mixture was obtained by manual stirring. In this

51 work, the ratio of tannin and GDE was variable, and the detailed formulations are

52 shown in Table 1.

[Table 1 near here]

2.2 Manufacture of three-layer plywood samples and measurement of shear

strength

56 Three-layer plywood was prepared by using tannin/GDE wood adhesives to bond

57 poplar veneers, with single spread of $150-160 \mathrm{~g} / \mathrm{m}^{2}$, and the hot-press gluing condition

58 are $1.25 \mathrm{MPa}$ at a temperature of $160^{\circ} \mathrm{C}$ for $6 \mathrm{~min}$. And then the dimension of

59 fabricated plywood sample was $200 \mathrm{~mm} \times 250 \mathrm{~mm} \times 5 \mathrm{~mm}$. All plywood samples were

60 standby at room condition for at least $24 \mathrm{~h}$ before cutting. After that each sample were

61 separated into 18 pieces of testing samples which had the dimension of $100 \mathrm{~mm} \times 25$

$62 \mathrm{~mm} \times 5 \mathrm{~mm}$ for measuring the dry and wet tensile force. For wet shear strength testing,

63 the plywood samples were soaked into cold tap water for $24 \mathrm{~h}$ and hot water $(63 \pm 3)^{\circ} \mathrm{C}$ 
64 for $3 \mathrm{~h}$ before measuring, according to the Chinese National Standard (GB/T

65 17657-2013). Six repeated samples were measured for the mean values and standard

66 deviations.

\subsection{Measurement of some basic properties of tannin/GDE wood adhesives}

69 The $\mathrm{pH}$ values of the series of tannin/GDE wood adhesives were measured by using

70 PHS-3C vale meter; The viscosity of those adhesives was tested with Brookfield

71 DV-II+ Viscometer, utilizing spindle No. 4 with $30 \mathrm{rpm}$ at room condition; Taking

72 small amount of wood adhesive samples ( $3 \mathrm{~g}$, recorded as $\left.\mathrm{W}_{1}\right)$ were putted into oven

73 and heated them with $105 \pm 2{ }^{\circ} \mathrm{C}$ till the weight difference between two adjacent times is

74 less than $0.02 \mathrm{~g}$, recorded as $\mathrm{W}_{2}$. The non-volatile resin solid content was calculated

75 by the following formula:

76 Solid content $=\mathrm{W}_{2} / \mathrm{W}_{1} \times 100 \%$

\section{$77 \quad$ 2.3.2 Hydrolysis residual rate calculating}

78 Taking some liquid wood adhesive and put them into oven at $103 \pm 2^{\circ} \mathrm{C}$ till the constant

79 weight was obtained, recorded as $\mathrm{M}_{1}$. And then put those dried adhesive samples into

80 the hot water at $60^{\circ} \mathrm{C}$ for $6 \mathrm{~h}$. After that taking the immersed samples and putting them

81 into oven again at $105^{\circ} \mathrm{C}$ till the weight difference between two adjacent times is less

82 than $0.02 \mathrm{~g}$, recorded as $\mathrm{M}_{2}$. The residual rate was calculated by the following

83 formula:

84 Hydrolysis residual rate $=\mathrm{M}_{2} / \mathrm{M}_{1} \times 100 \%$ 
85 Five repeated measurement were carried out, which were calculated for the mean

86 value and standard deviations.

87 2.3.3 Thermomechanical Analysis (TMA)

88 The relationship between modulus of elasticity (MOE) and temperature was recorded

89 and calculated by the inner-software procedure of TMA equipment (Mettler Toledo,

90 Zurich, Switzerland), which using three-point bending testing condition. Two pieces

91 of beech wood, with the size of $17 \times 5 \times 1.1 \mathrm{~mm}^{3}$ (Length $\times$ width $\times$ thickness), were

92 assembled with $30 \mathrm{mg}$ tannin/GDE wood adhesives to form a beech-resin-beech

93 sandwiches structure. And then put the testing sample on the testing scaffolding. The

94 testing was carried out between the perform temperature $30^{\circ} \mathrm{C}$ and $250^{\circ} \mathrm{C}$ with

95 non-isothermal mode. The heating rate is $10^{\circ} \mathrm{C}$ min with a constant value. Each sample

96 specimens were exercised a $0.1 / 0.5 \mathrm{~N}$ force cycle, which was lasted 12 seconds $(6 \mathrm{~s} / 6 \mathrm{~s})$

97 per cycle, on an $18 \mathrm{~mm}$ span.

$98 \quad$ 2.3.4 Thermogravimetric analysis (TGA)

99 The thermal stability of tannin/GDE was investigated by the TGA 5500 analysis

100 (Mettler Toledo, Guyancourt, France). About 5-8 mg dried sample powder was putted

101 on a platinum pan, and then heating the sample to the desire temperature at a heating

102 rate of $10^{\circ} \mathrm{C} / \mathrm{min}$, under a nitrogen atmosphere with the flow of $50 \mathrm{~mL} / \mathrm{min}$. The

103 testing temperature was range from $25^{\circ} \mathrm{C}$ to $790^{\circ} \mathrm{C}$

$104 \quad 2.4$ The reaction mechanism between tannin and GDE

105 2.4.1 Fourier transform infrared spectroscopy (FT-IR) 
106 The tannin or tannin/GDE samples were cured at $120 \pm 2^{\circ} \mathrm{C}$ for $2 \mathrm{~h}$, and then got the

107 powder by mortar. A small amount of sample powder was placed into a diamond eye

$108(1.8 \mathrm{~mm})$ of the ATR equipment (PerkinElmer Frontier ATR-FTMIR). And then

109 tightly screwing the clamp device, ensuring the samples were contacted with

110 transparent glass of the bottle of diamond eye close-knit. The scan results of each

111 sample were recorded with 32 scans between the wave range of 600 and $4000 \mathrm{~cm}^{-1}$,

112 with the scan resolution of $4 \mathrm{~cm}^{-1}$.

\section{2.4.2 Matrix Assisted Laser Desorption Ionization Time-of-Flight (MALDI-TOF)}

114 The samples for matrix-assisted laser desorption ionization time-of-flight

115 (MALDI-TOF) analysis were homogeneous covered on the locations dedicated 116 analysis plaque before testing. Briefly, about $5 \mathrm{mg}$ of samples were dissolved into 1

$117 \mathrm{ml}$ water/acetone mixture solution of 50:50 v/v firstly. And then, taking $10 \mathrm{mg}$ of the 118 above solution, letting them mixed with $10 \mu \mathrm{l}$ of a 2,5-dihydroxy benzoic acid (DHB)

119 matrix to form a homogenous mixture and standby. Before covering with samples, the 120 corresponding of locations dedicated analysis plaque were needed to cover with $2 \mu 1$

$121 \mathrm{NaCl}$ solution, which is the $0.1 \mathrm{M}$ in $2: 1 \mathrm{v} / \mathrm{v}$ methanol/water solution, and pre-dried.

122 Finally, taking $1 \mu \mathrm{l}$ sample solution and then covered on the corresponding of

123 locations dedicated analysis plaque and dried.

124 Red phosphorous was act as reference sample to standardize the device before testing

125 each time. The MALDI-TOF spectra were obtained by using the Axima-Performance 126 mass spectrometer from Shimadzu Biotech (Kratos Analytical Shimadzu Europe Ltd.,

127 Manchester, UK). And the testing was carried out with a linear polarity-positive 
128 tuning mode. The measurements were taken by making 1000 profiles per sample with

129 two shots accumulated per profile. The accuracy of the spectrum is $\pm 1 \mathrm{Da}$.

$130 \quad$ 2.4.3 Cross Polarization-Magic Angle Spinning (CP-MAS $\left.{ }^{13} \mathrm{C} N \mathrm{MR}\right)$

131 To investigate the chemical structure of tannin/GDE sample, CP-MAS ${ }^{13} \mathrm{C}$ NMR 132 equipment was utilized. The spectra result was got by the AVANCE II $400 \mathrm{MHz}$

133 spectrometer (Brüker, Billerica, MA, USA), which using $4 \mathrm{~mm}$ probe at a $12-\mathrm{kHz}$

134 sample spin. The pulse duration time was $4.1 \mu$ s at $90^{\circ}$, and the contact time is $2 \mathrm{~ms}$

135 with a recycling delay of $4 \mathrm{~s}$. The tetramethyl silane (TMS) was served as control 136 reference simple to determine the chemical shifts. The accuracy of the spectrum is \pm $1371 \mathrm{ppm}$.

\section{Results and discussion}

\section{3.1 The basic characterizations of tannin/GDE wood adhesive}

140 A novel mimosa tannin-based high-performance wood adhesive was obtained by

141 mixing tannin with glycerol diglyceryl ether (GDE) at room temperature in distilled 142 water. GDE was chosen as crosslinker due to its lower toxicity than other epoxies ${ }^{[30-33]}$

143 to provide further bond strength to the tannin. The most effective functional approach

144 which originates from using GDE is that non-hydrolysable ether bonds can be formed

145 with the tannin during the wood panels hot-pressing ${ }^{[3]}$. These ethers are obtained by

146 the reaction of the tannin -OHs with the epoxy groups of GDE by water elimination,

147 meanwhile, they could presumably simultaneously enhance the stability of the cured 148 resins by limiting resin degradation through hydrolytic pathways ${ }^{[3]}$. Therefore, 
149 tannin/GDE wood adhesives show a good bonding performance and water resistance.

150 Table 2 shows the basic characterizations of tannin/GDE wood adhesives. The $\mathrm{pH}$

151 values are all around 5 and 5.5. There does not appear to be any major difference in

152 solids content, all being in the $63.5 \%-65.3 \%$ range. The viscosity of these adhesives,

153 however, is significantly different, a higher viscosity being obtained for the higher

154 proportions of tannin. The tannin: GDE weight ratios from 1:1, 2:1 and 3:1, present

155 viscosities of $3100 \pm 156,5600 \pm 192$ and $6480 \pm 135 \mathrm{mPa} \cdot \mathrm{s}$, respectively. This indicates

156 that GDE can effectively dilute the concentration of tannin/water solution so as to

157 obtain a relatively lower viscosity than when the ratio of tannin/GDE is $1: 1$.

[Figure 1 near here]

[Table 2 near here]

\subsection{Performance Analysis of tannin/GDE wood adhesive}

161 3.2.1 Thermomechanical analysis (TMA)

162 The thermomechanical analysis curves have shown in Figure 2, which show the

163 variation of Young's modulus E (MOE) as a function of curing temperature ${ }^{[7,23]}$. A

164 higher MOE is obtained by increasing the proportion of GDE, with the highest MOE

165 being almost $7100 \mathrm{MPa}$ when the ratio of tannin/GDE is 1:1, with the MOE becoming

$1665300 \mathrm{MPa}$ and $4800 \mathrm{MPa}$ for tannin/GDE-2/1 and tannin/GDE-3/1, respectively. This

167 infers that tannin/GDE-1/1 gives the best bonding performance and this decreases for

168 decreasing GDE proportions. Existing literature confirms this ${ }^{[7,23,32,33]}$. The shear

169 strength of bonded specimens with tannin/GDE adhesives also confirms this trend. 
170 Even though these wood adhesives start curing at the same initial temperature, around

$171125^{\circ} \mathrm{C}$, the highest MOE occurs at different temperatures for the different cases. Thus,

172 for tannin/GDE-1/1, tannin/GDE-2/1 and tannin/GDE-3/1, the obtained maximum

173 elastic modulus temperature is $170^{\circ} \mathrm{C}, 154^{\circ} \mathrm{C}$ and $149^{\circ} \mathrm{C}$, respectively. It is most likely

174 that more non-hydrolysable ether bonds could be formed during hot-pressing GDE

175 increases. Therefore, more energy (a higher temperature) is needed during hot

176 pressing to obtain a higher MOE and to form non-hydrolysable ether bonds. Figure 2

177 shows the MOE value sequence relationships clearly, i.e. tannin/GDE-1/1,

178 tannin/GDE-2/1 and tannin/GDE-3/1. It can be speculated that the tannin/GDE

179 adhesive has a higher thermal stability with higher proportion of $\operatorname{GDE}^{[33]}$. This kind of

180 result can be deduced from the results of the thermogravimetric analysis.

[Figure 2 near here]

182 3.2.2 Thermogravimetric analysis (TGA)

183 To investigate the thermal stability of fully cured series Tannin/GDE wood adhesives,

184 thermogravimetric analysis (TGA) was carried out. The corresponding results curves

185 of each samples and their first derivatives (DTG) are shown in Figure 3. There

186 appears to be a three-stages thermal degradation process, thus, in the $50-150^{\circ} \mathrm{C}$,

$187150-400^{\circ} \mathrm{C}$ and $400-600^{\circ} \mathrm{C}$. DTG curves show three peaks as well, corresponding to the

188 three thermal degradation stages. For the first one, in the low-temperature range, this

189 weight loss was attributed to the residual water evaporation and some small molecular

190 impurities degradation ${ }^{[34,35]}$. The second stage occurs in the $150-400^{\circ} \mathrm{C}$ range, a small

191 peak appearing in this temperature range, which corresponds to some unreacted 
$192 \mathrm{GDE}^{[3]}$. This is confirmed by the peak increasing at the higher proportions of GDE.

193 Finally, the third degradation stage showing a large weight loss can occur in the

$194400-600^{\circ} \mathrm{C}$ range, is due to the degradation of the cured adhesive skeleton. Some more

195 stable chemical bonds, such as $\mathrm{C}-\mathrm{C}$ and $\mathrm{C}-\mathrm{O}$, are cleaved within this temperature

196 range ${ }^{[34-36]}$. Remarkably, the degradation temperature peak shifts to a higher value,

197 while the weight loss rate shifts to smaller value with the increase in GDE. FT-IR

198 analysis shows a new bond structure being obtained during the curing process. Thus, a

199 new structure appears to be formed during the curing process, this contributing to 200 improve thermal stability of the wood adhesive.

[Figure 3 near here]

$202 \quad$ 3.2.3 Hydrolysis residual rate analysis

203 The hydrolysis residual rate is a parameter commonly used as an indicator to assess

204 the hydrolytic stability of a cured wood adhesive ${ }^{[20]}$. It can be calculated by using the

205 weight difference between the original weight of an adhesive and its non-hydrolyzable

206 portion after a specific hydrolysis treatment ${ }^{[11-13]}$. The results for the tannin/GDE

207 wood adhesives are shown in Table 3. As the proportion of tannin increases, the

208 residual rate shows a decreasing trend, the lowest rate being $90.05 \pm 0.037$ for

209 tannin/GDE-3/1. This indicates that the tannin/GDE-3/1 adhesive has the lowest

210 proportion of non-hydrolysable material, thus poorer crosslinking. The residual rate

211 increases with the decreasing amount of tannin, increased of $4 \%$ to $94.41 \pm 0.031$ for

212 the tannin/GDE 2:1. This is so because of more non-hydrolysable ether bonds being

213 formed. Same trend for the tannin/GDE-1/1 improved $6 \%$ to $96.29 \pm 0.023$. These 
214 results are consistent with other research work using epoxy resin to improve bonding

215 performance ${ }^{[37,38]}$. In addition, better bonding strength can be obtained by increasing

216 GDE but unfortunately to the expense of decreasing the proportion of biomaterials.

\subsection{The bonding performance of tannin/GDE wood adhesives}

219 To determine the bonding performance of the tannin/GDE wood adhesive, the dry, 24

$220 \mathrm{~h}$ cold water and $3 \mathrm{~h}$ hot water shear strengths of the plywood bonded with them were

221 measured. The results are shown in Figure 4. It can be seen that except for the $3 \mathrm{~h}$ hot

222 water treatment wet shear strength of the tannin/GDE-3/1 adhesive, all shear strength

223 values meet the interior-use plywood requirements of China national standard (GB/T

224 9846-2015, $\geq 0.7 \mathrm{MPa}$ ). All tannin/GDE resins show an outstanding bonding

225 performance for the dry and $24 \mathrm{~h}$ cold water shear strength. As expected, the shear

226 strength of the tannin/GDE adhesives increases by increasing the amount of GDE. For

227 the tannin/GDE-1/1 adhesive shows the highest shear strength, namely $1.61 \mathrm{MPa}$ for

228 dry strength, $1.37 \mathrm{MPa}$ for $24 \mathrm{~h}$ cold water wet strength and $1.19 \mathrm{MPa}$ for $3 \mathrm{~h}$ hot

229 water shear strength, respectively. The causes of this results are more

230 non-hydrolysable ether bonds have formed with the high amount of GDE. This

231 conclusion is in line with the results for the residual rate. The GDE, most probably,

232 acts in two ways: The first and most probable one is that the epoxy groups of GDE

233 can react with -OH groups of tannin, resulting in tannin/GDE derived macromolecules

234 forming the 3-D crosslinked network. The second one is that epoxy groups of GDE 
could also react with the - $\mathrm{OH}$ groups of the wood panels surface, but this is the less

236 likely possibility. Hence, the poorer trend for shear strength of tannin/GDE-2/1 and

237 tannin/GDE-3/1 compared to the tannin/GDE-1/1 adhesive. As shown in Figure 4, the

238 shear strength of tannin/GDE-2/1 adhesive is $1.29 \mathrm{MPa}$ for dry strength, $1.07 \mathrm{MPa}$ for

$23924 \mathrm{~h}$ cold water wet strength and $0.82 \mathrm{MPa}$ for $3 \mathrm{~h}$ hot water wet strength, respectively,

240 while the dry shear strength and $24 \mathrm{~h}$ cold water shear strength are $1.09 \mathrm{MPa}$ and 0.83

$241 \mathrm{MPa}$ for the tannin/GDE-3/1 adhesive, these too having reached the relevant

242 requirements. These trends are also confirmed by the results of the TMA analysis and

243 of the residual rate. More water resistance compounds have formed during the

244 plywood hot-pressing with high amount of GDE to yield a better wet shear strength.

[Figure 4 near here]

\subsection{The reaction mechanism between tannin and GDE}

\subsubsection{Fourier Transform Infrared (FT-IR) spectra analysis}

248 For investigating the functional groups changing after cured adhesives, the Fourier

249 Transform Infrared (FT-IR) analysis was used to study the variation of functional 250 groups after adhesives curing. The resulting spectra are shown in Figure 5. Raw

251 tannin was used as control (black spectrum). The spectra of the tannin/GDE adhesives

252 present a similar chemical structure than raw tannin. An intense broad absorption band

253 (region I in Figure 5(a)) between $3200-3500 \mathrm{~cm}^{-1}$ is associated with -OH group of 254 aromatic and aliphatic stretching vibration ${ }^{[34,39,40]}$. Although here also have some 255 difference between all four samples, it is still unidentifiable if some change occurs in 
the number of $-\mathrm{OH}$ during the reaction between tannin and GDE. This is so because a

257 new -OH group will be generated by the opening of epoxide ring when GDE reacts

258 with the $-\mathrm{OH}$ group of tannin, leaving the same the apparent number of -OH groups.

259 Some characteristic peaks can be seen in the Figure 5(b), 1607, 1508 and $1447 \mathrm{~cm}^{-1}$

260 are related to stretching vibration peaks of aromatic ring of the tannin structure ${ }^{[20,41,42]}$.

261 The peak at $1022 \mathrm{~cm}^{-1}$ represents the C-O bond stretching vibration, which probably

262 originates from aliphatic $\mathrm{C}-\mathrm{OH}^{[20]}$.

263 Some apparent changes can be noticed. In Figure 4(a), 2933 and $2860 \mathrm{~cm}^{-1}$ in the 264 region $\mathrm{I}$ of the four samples, which are attributed to the $\mathrm{C}-\mathrm{H}$ bond vibration of $-\mathrm{CH}_{2}-$ 265 or/and $-\mathrm{CH}_{3}{ }^{[7,34]}$. Especially in the tannin/GDE wood adhesive samples, the ratio of 266 peaks in the contoured region $\mathbb{I}$ are clearly greater than in the raw tannin case. These $267-\mathrm{CH}_{2}-$ groups are mainly coming from the DGE and some carbohydrate impurities of 268 the tannin extract. According to some literatures, the peak of $910 \mathrm{~cm}^{-1}$ should be 269 attributed to oxirane rings if it cannot fully reaction with tannin ${ }^{[43]}$. Nevertheless, this 270 peak had disappeared after reaction with tannin. Therefore, one can consider that the 271 epoxide groups of GDE have fully reacted with the tannin. Moreover, further evidence 272 can be found in Figure 4(b) black dotted line, i.e. the peak of $1078 \mathrm{~cm}^{-1}$ is attributed to

273 an ether $-\mathrm{C}-\mathrm{O}-$ bond $^{[3]}$, obtained by the GDE reaction with the tannin. A small peak at $2741078 \mathrm{~cm}^{-1}$ can also be seen in the raw tannin, this being attributed to the tannin 275 heterocycle ring. This peak has increased clearly after reaction with GDE. Therefore, 276 these results can suggest that GDE has indeed reacted with the tannin. 
279 MALDI-TOF mass spectrometry is now used to determine the tannin oligomers

280 formed and their distribution ${ }^{[36,44,45]}$. As we all known, there are four typical oligomers,

281 which are shown in Figure 6, i.e. Fisetinidin $(272.3+2 \mathrm{H}=274.3 \mathrm{Da})$, Robinetinidin $282(288.3+2 \mathrm{H}=290.3$ Da $), \quad$ Catechin $(288.3+2 \mathrm{H}=290.3$ Da $)$ and Delphinidin $283(304.3+2 \mathrm{H}=306.3 \mathrm{Da})$, respectively, are the basic structure units of mimosa 284 tannin-based GDE wood adhesive. Therefore, some foreseeable reaction structures 285 can be speculated according to those monomer structural units. And the MALDI-TOF 286 spectrum of tannin/GDE-1/1 has been done and is shown in Figure 7.

[Figure 6 near here]

288 From Figure 7, some regular peak-to-peak gaps can be observed, giving a sequence of 289 peaks such as 273.9 Da, 544.4 Da and 819.4 Da; 560.5 Da and 831.0 Da; 1049.8 Da 290 and 1320.9 Da; $1561.4(1535.4+23)$ Da and 1806.8. A 272.3-274.3 Da $22 \mathrm{Da}$ (with or 291 without $\mathrm{Na}^{+}$) repeating unit is then present indicating that fisetinidin (Fi) units are 292 present in the sample $\mathrm{e}^{[45,46]}$.

293 Identically, a series of peaks, including 576.4 Da, 892.1 (866.7+23) Da, 1155 Da and 294 1443.3 Da; 784.7 Da, $1097.9(1073+23) \mathrm{Da}, 1631.2 \mathrm{Da}$ and 1639.0 Da, were 295 separated by a 288.3-290.3 Da 2 Da repeating units. Thus, robinetinidin (Ro) or 296 catechin $(\mathrm{Ca})$ repeating units, or both, are present ${ }^{[10,46]}$.

297 For the same reason, the presence of delphinidin (De) units at 304.3-306.3 Da $\pm 2 \mathrm{Da}$ 298 can be deduced from the series of peaks, such as $305.1 \mathrm{Da}, 608.5 \mathrm{Da}, 939.3(914.5+23)$

299 Da and 1222.1/1220.0 Da; 803.3 Da, 1101.7 Da and 1429.6 (1409.2+23) $\mathrm{Da}^{[45,46]}$. 
300 Moreover, because of reaction of tannin with GDE, it can more complex oligomers

301 are also obtained. And the complex obtained-structure always derived from the tannin

302 basic units linked by GDE. Evidence of these can be seen in Figure 7. For instance,

303 the peak at 768.9 Da probable is that GDE act as crosslinker to linked two tannin

304 oligomers:

305<smiles>[R20]CC(O)COCC(O)COCC(O)COC1Cc2c(O)cc(O)cc2OC1c1ccc(O)c(O)c1</smiles>

306 Or three kinds of tannin oligomers are linked by the GDE molecules, such as the peak

307 1278.5 Da:

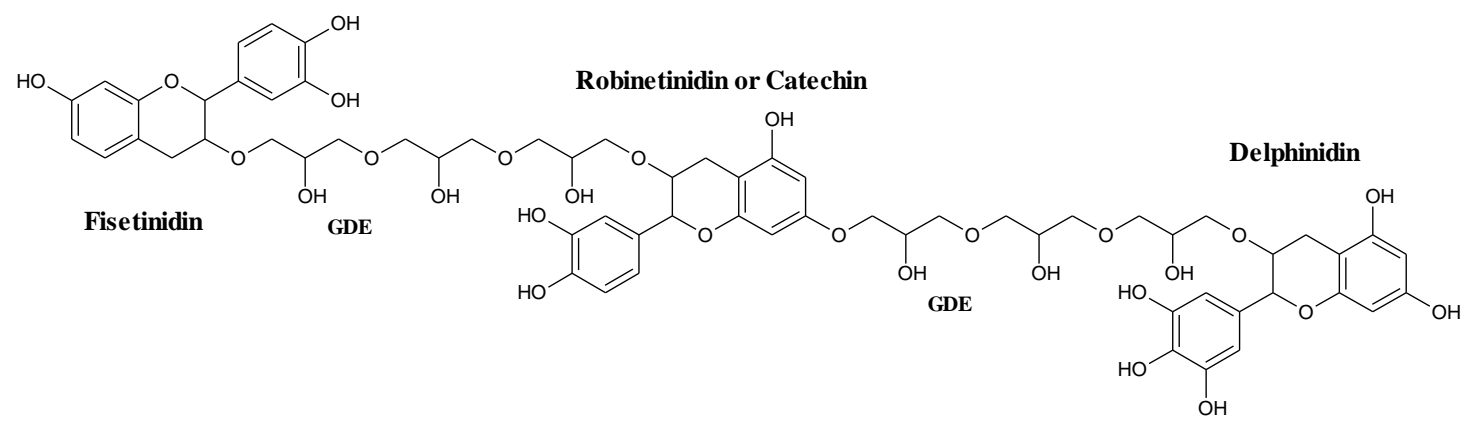

310 Furthermore, some large crosslinked molecules can be obtained by the present of

311 crosslinker GDE, such as the peak at $1561 \mathrm{Da}$

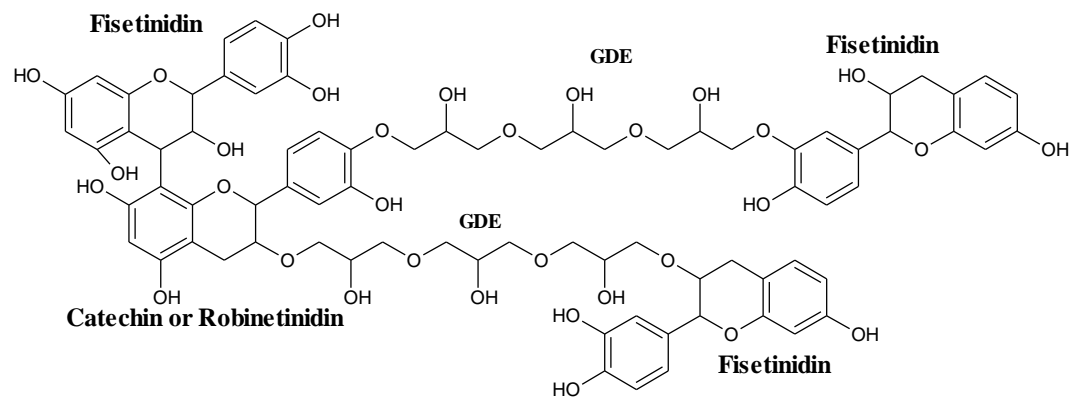


313 and or more complicated obtained structure, the peak at 2172.5 Da:

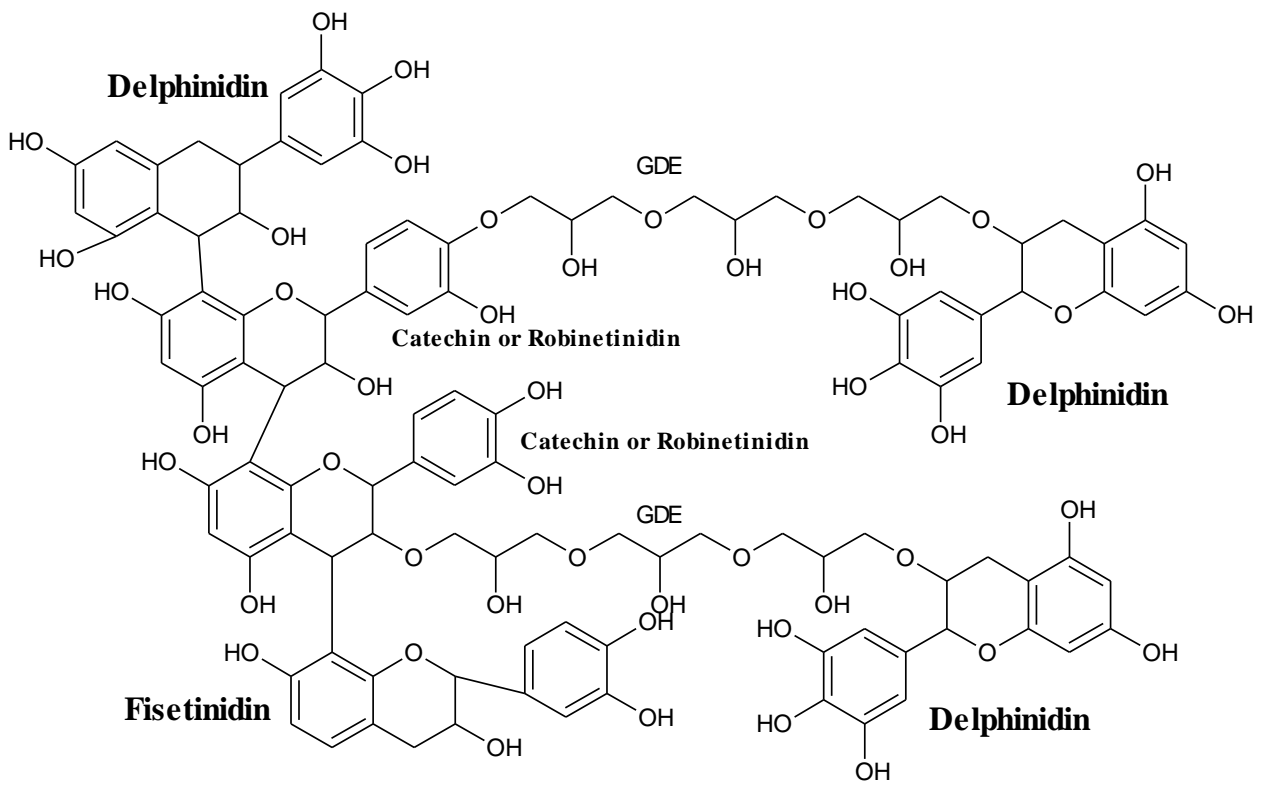

315 Hence, it can be deduced that GDE has reacted with the tannin during the curing

316 process. The abovementioned peaks and structures are only a few representative

317 formulas among the all peaks of MALDI-TOF spectrum, the more some foreseeable

318 tannin or GDE derived products where been speculated and listed in Table S1.

[Figure 7 near here]

\subsubsection{CP-MAS ${ }^{13}$ C NMR analysis}

321 CP-MAS ${ }^{13} \mathrm{C}$ NMR was used to investigate the tannin/GDE-1/1. The spectrum

322 obtained is shown in Figure 8. The relatively broad and intense peak at $69.04 \mathrm{ppm}$ is

323 possibly a composite peak. It is composed of the alcohol -OHs of the carbohydrates

324 oligomers still present in the tannin extract ${ }^{[47]}$. This broad peak is superimposed on

325 and composed too of the $72 \mathrm{ppm}$ signal being the alcoholic $-\mathrm{OH}$ on the tannin

326 heterocycle ring at $\mathrm{C}_{3}{ }^{[47,48]}$. Secondly, it is superimposed/constituted on the products

327 from the tannin $\mathrm{C}_{3}-\mathrm{OH}$ reacted with $\mathrm{GDE}$, and possibly of the tannin extract 328 carbohydrate residues with the GDE too, so that structures such as 
$-\mathrm{O}-\mathrm{CH}_{2}-\mathrm{CH}_{2} \mathrm{OH}-\mathrm{CH}_{2}-\mathrm{R}$ can be obtained, which should have a shift of $70.7 \mathrm{ppm}^{[44]}$.

330 Therefore, the center of this composite peak at $69.04 \mathrm{ppm}$ can indicate that the

331 reaction has occurred between tannin extract components and GDE and that their

332 reaction site is on the tannin $\mathrm{C}_{3}$ position, but opens the possibility that the tannin

333 extract carbohydrate residues have also reacted with GDE. In addition, the peak at

$33440.8 \mathrm{ppm}$ is related to the $-\mathrm{CH}_{2}$-bridges, involving the $\mathrm{GDE}$ or the derived products of

335 GDE. Furthermore, a small shoulder peak at $154.45 \mathrm{ppm}$, which possible belongs to

336 the $\mathrm{C}_{5}$ or $\mathrm{C}_{7}$ of A-aromatic ring ${ }^{[44,47,48]}$. The peak at $150.14 \mathrm{ppm}$ is possibly the

337 structure obtained from the GDE reacted with tannin at the site $\mathrm{C}_{5}{ }^{[44]}$, while the peak

338 at $133.42 \mathrm{ppm}$ is the $\mathrm{C} 1$ ' of flavonoid units ${ }^{[47]}$. However, compared with the peak

$33969.04 \mathrm{ppm}$, it can be speculated that GDE mostly can react with tannin at its $\mathrm{C}_{3}$ site

340 with the clear possibility that it has reacted also with the tannin extract carbohydrates.

341 The peak at $40.6 \mathrm{ppm}$ indicates the presence of a certain extent rearrangement of the

342 tannin to catechinic acid, an unwanted rearrangement that cannot be completely

343 avoided ${ }^{[49,50]}$. The peak characteristic of epoxy groups should appear at $46.4 \mathrm{ppm}$, but

344 this kind of peak cannot be detected which indicates that the GDE has fully reacted

345 with the tannin extract.

[Figure 8 near here]

\section{Conclusions}

348 A series of tannin-based wood adhesives were prepared via mixing commercial

349 Mimosa tannin and GDE directly without any pre-treatment. In addition, this series of 
350 adhesives present a good bonding performance and water resistance due to the present

351 of non-hydrolysable ether bonds which are formed by reaction of tannin and GDE.

352 The tannin/GDE-1/1 adhesive shows the highest shear strength, namely 1.61 MPa for

353 dry strength, $1.37 \mathrm{MPa}$ for $24 \mathrm{~h}$ cold water wet strength and $1.19 \mathrm{MPa}$ for $3 \mathrm{~h}$ hot

354 water shear strength, respectively. Moreover, the residual rate can be improved by the

355 GDE addition and present a positive correlation trend. With the increasing of GDE

356 addition, its residual rate passed from 90.05 for tannin/GDE-3/1 to 96.29 for

357 tannin/GDE-1/1, hence it was improved by over $6 \%$. Furthermore, the thermal

358 stability has improved and exhibits the same trend as the residue rate. From the results

359 obtained by FT-IR, MALDI-TOF and ${ }^{13} \mathrm{C}$ NMR, the typical reaction between tannin

360 and GDE has occurred between the epoxy groups of GDE with -OH groups of the

361 tannin extract, resulting in non-hydrolysable ether bonds. Furthermore, these ether

362 bonds are most likely sited at the $\mathrm{C}_{3}$ of the flavonoid units heterocyclic ring, of the

363 carbohydrate oligomer residues in the tannin extract, and $\mathrm{C}_{5}$ or $\mathrm{C}_{7}$ site of A-ring,

364 according to the ${ }^{13} \mathrm{C}$ NMR results.

\section{Acknowledgement}

366 This work was supported by the National Natural Science Foundation of China

367 (NSFC 31971595), Yunnan provincial youth and middle-age reserve talents of

368 academic and technical leaders (2019HB026), Scholarship from China Scholarship

369 Council (CSC), Yunnan Provincial Key Laboratory of Wood Adhesives and Glued

370 Products and The LERMAB is supported by a grant of the French Agence Nationale 
371 de la Recherche (ANR) as part of the laboratory of excellence (LABEX) ARBRE.

\section{References}

373 [1] Wilson, J.B. Life-cycle inventory of medium density fiberboard in terms of

374 resources, emissions, energy and carbon. Wood and Fiber Science, 2010, 42(CORRIM

375 Special Issue), 107-124.

376 [2] Salthammer, T.; Mentese, S.; Marutzky, R. Formaldehyde in the indoor

377 environment. Chemical reviews, 2010, 110(4), 2536-2572. DOI: 10.1021/cr800399g.

378 [3] Li, R.J.; Gutierrez, J.; Chung, Y. L.; Frank, C. W.; Billington, S. L.; Sattely, E. S.

379 A lignin-epoxy resin derived from biomass as an alternative to formaldehyde-based 380 wood adhesives. Green chemistry, 2018, 20(7), 1459-1466. DOI:10.1039/c7gc03026f 381 (2018).

382 [4] Aziz, N. A.; Latip, A. F. A.; Peng, L. C.; Abd Latif, N. H.; Brosse, N.; Hashim, R.;

383 Hussin, M. H. Reinforced lignin-phenol-glyoxal (LPG) wood adhesives from coconut 384 husk. International journal of biological macromolecules, 2019, 141, 185-196. DOI:

385 10.1016/j.ijbiomac.2019.08.255.

386 [5] Chen, H.; Nair, S. S.; Chauhan, P.; Yan, N. Lignin containing cellulose nanofibril 387 application in pMDI wood adhesives for drastically improved gap-filling properties 388 with robust bondline interfaces. Chemical Engineering Journal, 2019, 360, 393-401.

389 DOI: $10.1016 /$ j.cej.2018.11.222.

390 [6] Hussin, M. H.; Aziz, A. A.; Iqbal, A.; Ibrahim, M. N. M.; Abd Latif, N. H. 391 Development and characterization novel bio-adhesive for wood using kenaf core 
392 (Hibiscus cannabinus) lignin and glyoxal. International journal of biological

393 macromolecules, 2019, 122, 713-722. DOI: 10.1016/j.ijbiomac.2018.11.009.

394 [7] Chen, X.; Xi, X.; Pizzi, A.; Fredon, E.; Du, G. ; Gerardin, C.; Amirou, S.

395 Oxidized demethylated lignin as a bio-based adhesive for wood bonding. The Journal 396 of Adhesion, 2020, 1-18. DOI: 10.1080/00218464.2019.1710830.

397 [8] Hoong, Y.B.; Paridah, M.T.; Luqman, C. A.; Koh, M. P.; Loh, Y. F. Fortification 398 of sulfited tannin from the bark of Acacia mangium with phenol-formaldehyde for use 399 as plywood adhesive. Industrial Crops and Products, 2009, 30(3), 416-421. 400 DOI:10.1016/j.indcrop.2009.07.012.

401 [9] Moubarik, A.; Pizzi, A.; Allal, A.; Charrier, F.; Charrier, B. Cornstarch and tannin 402 in phenol-formaldehyde resins for plywood production. Industrial Crops and 403 Products, 2009, 30(2), 188-193. DOI: 10.1016/j.indcrop.2009.03.005.

404 [10]Li, J.; Zhu, W. ; Zhang, S. ; Gao, Q. ; Xia, C. ; Zhang, W. ; Li, J. 405 Depolymerization and characterization of Acacia mangium tannin for the preparation 406 of mussel-inspired fast-curing tannin-based phenolic resins. Chemical Engineering 407 Journal, 2019, 370, 420-431. DOI:10.1016/j.cej.2019.03.211.

408 [11] Yue, L.; Shi, R.; Yi, Z.; Shi, S. Q.; Gao, Q.; Li, J. A high-performance soybean 409 meal-based plywood adhesive prepared via an ultrasonic process and using 410 significantly lower amounts of chemical additives. Journal of Cleaner Production, 411 2020, 274, 123017. DOI: 10.1016/j.jclepro.2020.123017.

412 [12]Xu, Y.; Xu, Y.; Zhu, W.; Zhang, W.; Gao, Q.; Li, J. Improve the performance of 413 soy protein-based adhesives by a polyurethane elastomer. Polymers, 2018, 10(9), 
414 1016. DOI: 10.3390/polym10091016.

415 [13]Chen, M.; Luo, J.; Shi, R.; Zhang, J.; Gao, Q.; Li, J. Improved adhesion

416 performance of soy protein-based adhesives with a larch tannin-based resin. Polymers,

417 2017, 9(9), 408. DOI: 10.3390/polym9090408.

418 [14]Wang, Z.; Zhu, H.; Huang, J.; Ge, Z.; Guo, J.; Feng, X.; Xu, Q. Improvement of

419 the bonding properties of cassava starch-based wood adhesives by using different

420 types of acrylic ester. International journal of biological macromolecules, 2019, 126,

421 603-611. DOI: 10.1016/j.ijbiomac.2018.12.113.

422 [15]Li, P.; Wu, Y.; Zhou, Y.; Zuo, Y. Preparation and characterization of

423 resorcinol-dialdehyde starch-formaldehyde copolycondensation resin adhesive.

424 International journal of biological macromolecules, 2019, 127, 12-17. DOI:

425 10.1016/j.ijbiomac.2018.12.249.

426 [16] Jiang, W.; Kumar, A.; Adamopoulos, S. Liquefaction of lignocellulosic materials

427 and its applications in wood adhesives-A review. Industrial Crops and Products, 2018,

428 124, 325-342. DOI: 10.1016/j.indcrop.2018.07.053.

429 [17]Alma, M. H.; Basturk, M. A. Liquefaction of grapevine cane (Vitis vinisera L.)

430 waste and its application to phenol-formaldehyde type adhesive. Industrial crops and

431 products, 2006, 24(2), 171-176. DOI: 10.1016/j.indcrop.2006.03.010.

432 [18] Alma, M. H.; Baştürk, M. A.; Shiraishi, N. Cocondensation of NaOH-catalyzed

433 liquefied wood wastes, phenol, and formaldehyde for the production of resol-type

434 adhesives. Industrial \& engineering chemistry research, 2001, 40(22), 5036-5039.

435 DOI: $10.1021 / \mathrm{ie} 000858 x$. 
[19] Shirmohammadli, Y.; Efhamisisi, D.; Pizzi, A. Tannins as a sustainable raw

437 material for green chemistry: A review. Industrial Crops and Products, 2018, 126,

438 316-332. DOI:10.1016/j.indcrop.2018.10.034.

439 [20]Liu, J.; Wang, L.; Li, J.; Li, C.; Zhang, S.; Gao, Q.; Zhang, W.; Li, J. Degradation 440 mechanism of Acacia mangium tannin in $\mathrm{NaOH} / \mathrm{urea}$ aqueous solution and

441 application of degradation products in phenolic adhesives. International Journal of

442 Adhesion and Adhesives, 2020, 98, 102556. DOI: 10.1016/j.ijadhadh.2020.102556.

443 [21]Pizzi, A. Recent developments in eco-efficient bio-based adhesives for wood 444 bonding: opportunities and issues. Journal of adhesion science and technology, 2006, 445 20(8), 829-846. DOI:10.1163/156856106777638635.

446 [22]Kamoun, C.; Pizzi, A. Mechanism of hexamine as a non-aldehyde 447 polycondensation resins hardener. Part 1: Hexamine decomposition and reactive 448 intermediates. Holzforschung und Holzverwertung, 2000, 52(1), 16-19.

449 [23]Efhamisisi, D. ; Thevenon, M. F. ; Hamzeh, Y. ; Karimi, A. N. ; Pizzi, A. ; 450 Pourtahmasi, K. Induced tannin adhesive by boric acid addition and its effect on 451 bonding quality and biological performance of poplar plywood. ACS Sustainable 452 Chemistry \& Engineering, 2016, 4(5), 2734-2740. DOI:

453 10.1021/acssuschemeng.6b00230.

454 [24]Ballerini, A.; Despres, A.; Pizzi, A. Non-toxic, zero emission tannin-glyoxal 455 adhesives for wood panels. Holz als Roh-und Werkstoff, 2005, 63(6), 477-478. DOI: $45610.1007 / \mathrm{s} 00107-005-0048-\mathrm{x}$.

457 [25]Zhang, J.; Xi, X. ; Liang, J. ; Pizzi, A. ; Du, G. ; Deng, S. Tannin-based adhesive 
cross-linked by furfuryl alcohol-glyoxal and epoxy resins. International Journal of

459 Adhesion and Adhesives, 2019, 94, 47-52. DOI: 10.1016/j.ijadhadh.2019.04.012.

460 [26]Zhou, X.; Pizzi, A. Pine tannin based adhesive mixes for plywood. International

461 Wood Products Journal, 2014, 5(1), 27-32. DOI: 10.1179/204264531Y.0000000043.

462 [27]Faris, A. H.; Rahim, A. A.; Ibrahim, M. N. M.; Alkurdi, A. M.; Shah, I.

463 Combination of lignin polyol-tannin adhesives and polyethylenimine for the

464 preparation of green water- resistant adhesives. Journal of Applied Polymer Science,

465 2016, 133(20), 43437. DOI: 10.1002/app.43437.

466 [28]Xi, X.; Pizzi, A.; Frihart, C.; Lorenz, L.; Gerardin, C. Tannin plywood

467 bioadhesives with non-volatile aldehydes generation by specific oxidation of 468 mono-and disaccharides. International Journal of Adhesion and Adhesives, 2020, 98, 469 102499. DOI: 10.1016/j.ijadhadh.2019.102499.

470 [29]Navarrete, P.; Pizzi, A.; Tapin-Lingua, S.; Benjelloun-Mlayah, B.; Pasch, H.;

471 Rode, K.; Delmotte, L.; Rigolet, S. Low formaldehyde emitting biobased wood 472 adhesives manufactured from mixtures of tannin and glyoxylated lignin. Journal of 473 Adhesion Science and Technology, 2012, 26(10-11), 1667-1684. DOI: $474 \quad 10.1163 / 156856111 X 618489$.

475 [30]Ping, L.; Gambier, F.; Pizzi, A.; Guo, Z. D.; Brosse, N. Wood adhesives from 476 agricultural by-products: Lignins and tannins for the elaboration of particleboards. 477 Cellulose Chem. Technol, 2012, 46(7-8), 457-462.

478 [31] Ghahri, S.; Pizzi, A.; Mohebby, B.; Mirshokraie, A.; Mansouri, H. R. Soy-based, 479 tannin-modified plywood adhesives. The Journal of Adhesion, 2018, 94(3), 218-237. 
DOI: $10.1080 / 00218464.2016 .1258310$.

481 [32]Laigle, Y.; Kamoun, C.; Pizzi, A. Particleboard IB forcast by TMA bending in UF 482 adhesives curing. European Journal of Wood and Wood Products, 1998, 56(3), 483 154-154. DOI: $10.1007 / \mathrm{s} 001070050288$.

484 [33]Xi, X.; Liao, J.; Pizzi, A.; Gerardin, C.; Amirou, S.; Delmotte, L. 485 5-Hydroxymethyl furfural modified melamine glyoxal resin. The Journal of Adhesion, 486 2019, 1-19. DOI: 10.1080/00218464.2018.1561291.

487 [34]Chen, X.; Li, J.; Xi, X.; Pizzi, A.; Zhou, X.; Fredon, E.; Du, G. ; Gerardin, C. 488 Condensed tannin-glucose-based NIPU bio-foams of improved fire retardancy. 489 Polymer Degradation and Stability, 2020, 175, 109121. DOI: 490 10.1016/j.polymdegradstab.2020.109121 (2020).

491 [35]Luo, J.; Zhou, Y.; Gao, Q.; Li, J.; Yan, N. From wastes to functions: A new 492 soybean meal and bark-based adhesive. ACS Sustainable Chemistry \& Engineering, 493 2020, 8(29), 10767-10773. DOI: 10.1021/acssuschemeng.0c02413.

494 [36]Chen, X. ; Xi, X. ; Pizzi, A. ; Fredon, E. ; Zhou, X. ; Li, J. ; Gerardin, C. ; Du, G. 495 Preparation and Characterization of Condensed Tannin Non-Isocyanate Polyurethane 496 (NIPU) Rigid Foams by Ambient Temperature Blowing. Polymers, 2020, 12(4), 750. 497 DOI: 10.3390/polym12040750.

498 [37]Li, J.; Luo, J.; Li, X.; Yi, Z.; Gao, Q.; Li, J. Soybean meal-based wood adhesive 499 enhanced by ethylene glycol diglycidyl ether and diethylenetriamine. Industrial Crops 500 and Products, 2015, 74, 613-618. DOI: 10.1016/j.indcrop.2015.05.066.

501 [38]Luo, J.; Li, C.; Li, X.; Luo, J.; Gao, Q.; Li, J. A new soybean meal-based 
502 bioadhesive enhanced with 5, 5-dimethyl hydantoin polyepoxide for the improved

503 water resistance of plywood. RSC Advances, 2015, 5(77), 62957-62965. DOI:

504 10.1039/C5RA05037E.

505 [39]Ferdosian, F.; Yuan, Z.; Anderson, M.; Xu, C.C. Synthesis and characterization of 506 hydrolysis lignin-based epoxy resins. Industrial Crops and Products, 2016, 91, 507 295-301. DOI:10.1016/j.indcrop.2016.07.020.

508 [40] Younesi-Kordkheili, H.; Pizzi, A. (2020). Improving the properties of 509 urea-lignin-glyoxal resin as a wood adhesive by small addition of epoxy. International 510 Journal of Adhesion and Adhesives, 2020, 102, 102681.

511 doi:10.1016/j.ijadhadh.2020.102681.

512 [41]Xin, J.; Li, M.; Li, R.; Wolcott, M. P.; Zhang, J. Green Epoxy Resin System

513 Based on Lignin and Tung Oil and Its Application in Epoxy Asphalt. ACS Sustainable 514 Chemistry \& Engineering, 2016, 4, 2754-2761.

515 DOI:10.1021/acssuschemeng.6b00256.

516 [42] Jahanshahi, S.; Pizzi, A.; Abdulkhani, A.; Shakeri, A. Analysis and testing of

517 bisphenol A-Free bio-based tannin epoxy-acrylic adhesives. Polymers, 2016, 8(4), 143.

518 DOI: 10.3390/polym8040143.

519 [43]Zhang, S.; Liu, T.; Hao, C.; Wang, L.; Han, J.; Liu, H.; Zhang, J. Preparation of a 520 lignin-based vitrimer material and its potential use for recoverable adhesives. Green 521 Chemistry, 2018, 20(13), 2995-3000. DOI: 10.1039/c8gc01299g.

522 [44] Jahanshahi, S.; Pizzi, A.; Abdulkhani, A.; Doosthoseini, K.; Shakeri, A.; Lagel, M.

523 C.; Delmotte, L. MALDI-TOF, ${ }^{13} \mathrm{C}$ NMR and FT-MIR analysis and strength 
524 characterization of glycidyl ether tannin epoxy resins. Industrial Crops and Products,

525 2016, 83, 177-185. DOI:10.1016/j.indcrop.2015.11.067.

526 [45]Pasch, H.; Pizzi, A.; Rode, K. MALDI-TOF mass spectrometry of polyflavonoid

527 tannins. Polymer, 2001, 42(18), 7531-7539. DOI: 10.1016/S0032-3861(01)00216-6.

528 [46] Abdalla, S.; Pizzi, A.; Ayed, N.; Charrier, F.; Bahabri, F.; Ganash, A.

529 MALDI-TOF and ${ }^{13} \mathrm{C}$ NMR analysis of Tunisian Zizyphus jujuba root bark tannins.

530 Industrial Crops and Products, 2014, 59, 287-281.

531 DOI:10.1016/j.indcrop.2014.05.035.

532 [47]Pizzi, A. Advanced wood adhesives technology; CRC Press: New York, 1994.

533 [48]Nicollin, A.; Zhou, X.; Pizzi, A.; Grigsby, W.; Rode, K.; Delmotte, L.

534 MALDI-TOF and ${ }^{13} \mathrm{C}$ NMR analysis of a renewable resource additive-Thermoplastic

535 acetylated tannins. Industrial crops and products, 2013, 49, 851-857. DOI:

536 10.1016/j.indcrop.2013.06.013.

537 [49] Pizzi, A.; Stephanou, A. A comparative ${ }^{13}$ C NMR study of polyflavonoid tannin

538 extracts for phenolic polycondensates. Journal of applied polymer science, 1993,

539 50(12), 2105-2113. DOI: 10.1002/app.1993.070501209.

540 [50]Navarrete, P.; Pizzi, A.; Bertaud, F; Rigolet, S. Condensed tannin reactivity

541 inhibition by internal rearrangements: Detection by CP-MAS ${ }^{13} \mathrm{C}$ NMR. Maderas:

542 Ciencia y tecnología, 2011, 13(1), 59-68. DOI: 10.4067/S0718-221X2011000100006. 